\title{
A comprehensive assessment of turbulence at a tidal- stream energy site influenced by wind-generated ocean waves
}

\author{
Thiébaut Maxime 1, ${ }^{*}$, Filipot Jean-Francois ${ }^{1}$, Maisondieu Christophe ${ }^{2}$, Damblans Guillaume ${ }^{1}$, \\ Duarte Rui ${ }^{1}$, Droniou Eloi ${ }^{3}$, Chaplain Nicolas ${ }^{4}$, Guillou Sylvain ${ }^{5}$
}

\author{
${ }^{1}$ France Énergies Marines, Technopôle Brest-Iroise, 525 Avenue Alexis de Rochon, 29280, Plouzané, \\ France \\ 2 IFREMER, ZI Pointe du diable, 29280, Plouzané, France \\ 3 DynamOcean SARL, 57 Rue de Metz, 56000, Vannes, France \\ 4 iXblue, 46 Quai François Mitterand, 13600, La Ciotat, France \\ 5 Normandie Univ, UNICAEN, LUSAC, EA4253, Site Universitaire de Cherbourg, Rue Louis Aragon, BP \\ 78, 50130, Cherbourg-Octeville, France \\ * Corresponding author : Maxime Thiébaut, email address : Maxime.Thiebaut@ite-fem.org
}

\begin{abstract}
:
Velocity measurements collected by an upward-looking acoustic Doppler current profiler were used to provide the first study of ambient turbulence in Alderney Race. Turbulence metrics were estimated at middepth during peak flooding and ebbing tidal conditions. The dissipation rate $\varepsilon$ and the integral lengthscale (L) were estimated using two independent methods: the spectral method and the structure function method. The spectral method provided $\varepsilon$ and $(L)$ estimates with standard deviations twice lower than that obtained from the structure function method. Removal of wave and Doppler noise-induced bias when estimating the dissipation rate was shown to be a crucial step in turbulence characterization. It allowed for a significant refining in $(L)$ estimates derived from the spectral and structure function methods of 35 and 20 respectively. The integral lengthscale was found to be 2-3 times the local water depth. It is considered that these findings could be valuable for current turbine designers, helping them optimizing their designs as well as improving loading prediction through the lifetime of the machines.
\end{abstract}

\section{Highlights}

- The first study of ambient turbulence in Alderney Race is provided. Two independent methods are used to quantify turbulence metrics. Removal of wave and Doppler noise-induced bias is a crucial step. - The integral lengthscale was found to be 2-3 times the local water depth. Unique dataset of turbulence metrics computed at mid-depth are provided.

Keywords : Turbulence, Tidal energy, Wave, Doppler noise, ADCP, Alderney Race 


\section{Introduction}

In order to limit the impacts of climate change, it becomes an obligation for all societies to properly and fully exploit, the renewable energy resources at their disposal. Among them, the exploitation of tidal stream energy still lags behind other renewable resources, such as wind or solar energy. The delayed development of tidal energy is mainly due to harsher environmental conditions encountered by tidal-stream energy converters (TECs) such as salt induced corrosion, extreme turbulence, strong currents, shear and hence the velocity profile shape [1,2]. These environmental constraints affect the physical integrity of TECs and raise many uncertainties with regard to the cost effectiveness of any project of tidal energy conversion.

Whilst the characteristics of the mean flow (e.g., speed, direction, current magnitude asymmetry) are relatively simple to measure (e.g., $[3,4,5])$, a lack of confidence in the characteristics of the turbulent components of the flow has subsequently resulted in high levels of conservativeness being employed by turbine designers. Failures of early generations tidal turbines have been identified to be, in part, a consequence of a poor understanding of hydrodynamic loading on tidal turbines associated with turbulence [6,7].

Fatigue life prediction is of prime importance when designing and operating a tidal turbine. It impacts the Levelized Cost of Energy (LCoE) and in particular, drives operational and maintenance strategies. Furthermore, turbulence has been

URL: Maxime. Thiebaut@ite-fem.org (Maxime Thiébaut) 
found to strongly increasing the magnitude of the power fluctuations generated by TEC [8] and thus, deteriorating the quality of the electricity supply [9].

During the last decade, numerous studies were conducted to investigate turbulence and hydrodynamic interactions between turbines and the flow. However, much of the research has been carried out numerically (e.g., [2, 10, 11]) or at the laboratory scale under simplified and controlled conditions (e.g., [7, 12, 13]). Turbulence characterization in a real flow is considered to be of prime importance for, (i), tidal energy site assessment and, (ii), improving the ability, and thus the confidence, of shelf sea circulation models in reconstructing the flow dynamics. On the former, previous studies have shown limited success in matching observed turbulence metrics to ocean flow solvers (e.g., [14]). A major issue here is the wide range of length scales and time scales occuring in high Reynolds number flows, that make this problem non trivial. Although, numerous reports of attempts made to quantify the structure of the flow and associated turbulence have been recently reported (e.g., $[3,8,15,16,17])$, the turbulent features of the tidal flow are still poorly understood and described. This is indicative of the inherent technical (i.e., sensor movement, limited sampling rate) and theoretical (simplifying assumptions) difficulties occurring when acquiring and processing measurements of moving turbulent structures in first currents [18] and especially in highly energetic tidal environments such as Alderney Race.

Acoustic Doppler current profilers (ADCPs) using four diverging beams, are commonly used for flow characterization and TEC performance monitoring at tidal energy sites. Such instruments allow for the estimation of the turbulent kinetic energy (TKE) dissipation rate using either spectral (e.g., [3, 8, 15]) or structure function methods (e.g., [3, 19, 20]). Both independent methods require the identification of an inertial subrange, where the assumption of local isotropy holds $[21,22]$.

To date, both methods have been applied to measurements performed at sites with small amplitude surface waves or at depths where wave orbital velocities are negligible. However, at tidal energy sites exposed to swell, such as Alderney Race, the velocity associated with the orbital motions may be observed in measurements, thus inducing a wave-induced bias in the calculation of the dissipation rate. Recently, Scannell et al. [23] evidenced such a bias when applying the structure function method to ADCP measurements collected in the Celtic Sea (northwestern Europe). To remove this bias, the authors employed a modified structure function methodology which exploits the differing lengthscale dependencies of the contributions to the structure function resulting from turbulent and wave orbital motions.

The study performed by Filipot et al. [16] pointed out that waves strongly affect the energy-spectra of velocity time series collected by a four-beam RDI Workhorse sentinel $600 \mathrm{kHz}$ ADCP installed at the Paimpol-Bréhat tidal energy site, Northern Brittany, France. In this study, the authors proposed a wave-turbulence separation method based on the wave-coherence assumption. However, the turbulent motions were found to be coherent over the vertical making the wave-coherence assumption not valid, at least for the site of Pampol-Bréhat. An alternative approach was proposed, relying on the estimation of the wave spectrum from the ADCP pressure data. It showed good ability in retrieving the turbulent spectrum in environment combining wave and turbulence. However, this method does not allow retrieving the turbulent spectrum for frequency higher than $0.16 \mathrm{~Hz}$ since this value is the pressure cut-off frequency of the ADCP used in this study.

Alderney Race contains a significant tidal energy resource that if harnessed could provide electrical power to France and the United Kingdom. Alderney Race is exposed to both strong tidal currents and waves and the flow is generally altered by the irrotational wave kinematics, throughout the water column. Furthermore, a great deal of uncertainty is apparent, as to the effect of waves to turbulence [14] and the measurement of turbulence at tidal energy sites (e.g., [24]) as well as wave-current misalignment [25].

To date, no attempt at characterizing turbulence in Alderney Race has been reported. This paper aims at filling this 
gap by providing the first turbulence characterization at this highly tidal energy site. The focus is on ambient turbulence (i.e., natural turbulence before the installation of TEC) and the objective is to provide characteristic design conditions for tidal turbines. In this study both spectral and structure function method are used to quantify the dissipation rate $\varepsilon$. An attempt of removing the Doppler noise $[15,26,27]$ and wave-induced bias in $\varepsilon$ estimates is proposed with the objective of providing refined estimates of the turbulent lengthscales and timescales.

\section{Data collection and methods}

\subsection{Site description and $A D C P$ s deployment}

Velocity measurements presented here were performed in the eastern (French) sector of Alderney Race located west of the Cotentin Peninsula in Normandy, France (Fig. 1). The area of interest lies in a macrotidal environment with tidal ranges reaching $7 \mathrm{~m} \mathrm{[28].} \mathrm{Tidal} \mathrm{current} \mathrm{velocity} \mathrm{reaches} 4.5 \mathrm{~m} / \mathrm{s}$ at spring tide and $2.5 \mathrm{~m} / \mathrm{s}$ at neap tide (Fig. 2). Tidal variations of sea surface heights and currents are predominantly semi-diurnal and globally symmetric. Peak flood and ebb tidal velocities occur at high and low water levels respectively with slack water at mid-tide, the tidal current dynamics is thus referred to as progressive wave system. Tidal wave propagates northward during flood which lasts about 6 hours and then changes to southward direction for the next 6 hours.

Two RDI Workhorse $600 \mathrm{kHz}$ four-beam ADCPs, were deployed on the seafloor (31 m mean water depth) approximately $4 \mathrm{~km}$ offshore, west of the port of Goury (Fig. 1). The instruments were mounted on a specifically designed frame having the following features: $3.3 \mathrm{~m}$ long, $2.5 \mathrm{~m}$ wide and $2100 \mathrm{~kg}$ weight (Fig. 2). The ADCPs collected data over a 38-day period, from September 27 to November 03, 2017. The instruments were coupled, in a master-slave set-up and were set to record alternately the along-beam velocities at the pinging rate of $2 \mathrm{~Hz}$. This measurement scheme was chosen in order to avoid any interference between the beams of the two sensors. Velocities were recorded with $1.3 \mathrm{~m}$ vertical resolution (bin size), starting $2.2 \mathrm{~m}$ from the seafloor (the first bin). The average heading of the master ADCP was such that the opposite beams 1 and 2 were oriented in the streamwise direction of the tidal current, whereas beams 3 and 4 pointed in the spanwise direction. The average attitude parameters (heading $\theta_{h}$, pitch $\theta_{p}$ and roll $\theta_{r}$ ) were found to be: $\theta_{h}$ $=109.3^{\circ} \pm 0.3^{\circ}, \theta_{p}=2.65^{\circ} \pm 0.1^{\circ}$ and $\theta_{r}=2.7^{\circ} \pm 0.1^{\circ}$. The low standard deviations indicate that the frame remained stable throughout the deployment.

For the purpose of this paper, only measurements collected by the master ADCP were used for the turbulence characterization. Results obtained from the master-slave set-up will be fully exploited in a forthcoming study. This set-up allows for the full estimation of the Reynolds stress tensor as well as an accurate evaluation of the production rate $\mathcal{P}$ [29].

\subsection{Instruments performance and data quality}

A three steps quality control process was performed on the ADCP measurements. The first step ensures that the signal correlation associated with velocity measurements is within a coherent variation range. Velocity measurements associated with a correlation lower than a threshold value are invalidated and removed. In the present study, this threshold was set to 120 counts for each beam and vertical bin [30].

The second step consists in removing the interference range due to sidelobe contamination. In upward-looking ADCP deployment, the sea surface reflects the emitted acoustic signal much more strongly than the scatterers, thus, sidelobe energy can travel the shorter path directly to the surface and thereby include the echo of the surface "velocity" with the velocity measurements taken along the beams at any longer distance. This potential for interference strictly depends on the beam angle. In our study, ADCP with a $20^{\circ}$ beam angle were used. These instruments have the potential for sidelobe 
contamination at the last $6 \%$ of the profile [30]. Therefore, data in vertical bins that were in the top $6 \%$ of the water column or above the surface at each time step were removed. The resulting missing values were then interpolated using a third degree polynomial fit around the gap. Filling of missing values was only done for gaps smaller than 10 points $(5$ seconds).

Finally, the Goring and Nikora detecting spikes method [31] was applied to velocity data sequences. This method projects the velocity against its first and second derivative in order to construct an ellipsoid in three-dimensional phase space. The points lying outside the ellipsoid, designated as spikes, are removed and interpolated by a polynomial fitted to good data on either side of the spike event.

\subsection{Analysis techniques and metrics used for turbulence characterization}

\subsubsection{Wave orbital velocities}

The energy-spectra $S_{\zeta}(f)$ of the sea surface elevation times series were extracted from the ADCP measurements using WavesMon RDI software. Since WavesMon only handles power of 2 for the Fast Fourier transform (FFT), the number of samples for each energy-spectrum was set to 4096 which corresponds to 2097 seconds (i.e., 34.95 minutes). This time interval is a good compromise between variability of the tidal flow and noise reduction in the energy-spectra $S_{\zeta}(f)$.

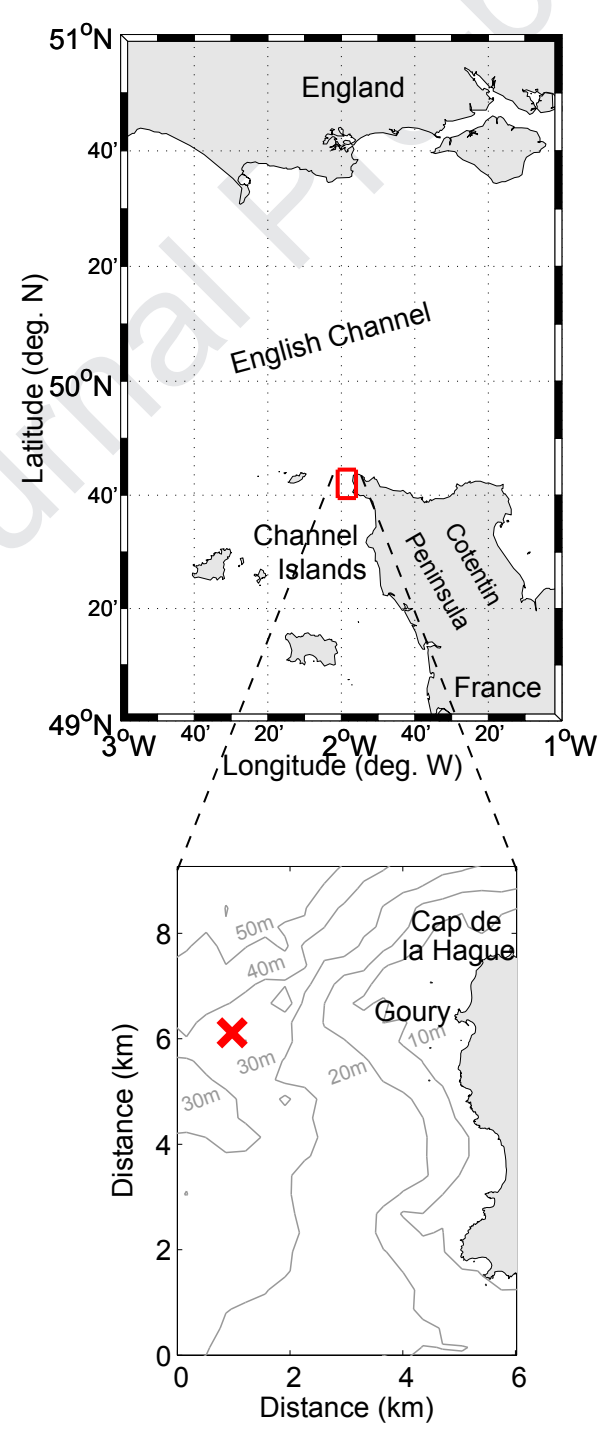

Figure 1: Upper panel: Map of the central part of the English Channel. Lower panel: The eastern part of Alderney Race with bathymetry (m) given in gray. Red cross denotes the location of the master and slave bottom-mounted ADCPs deployment site. Geographic names used in the text are also shown. 


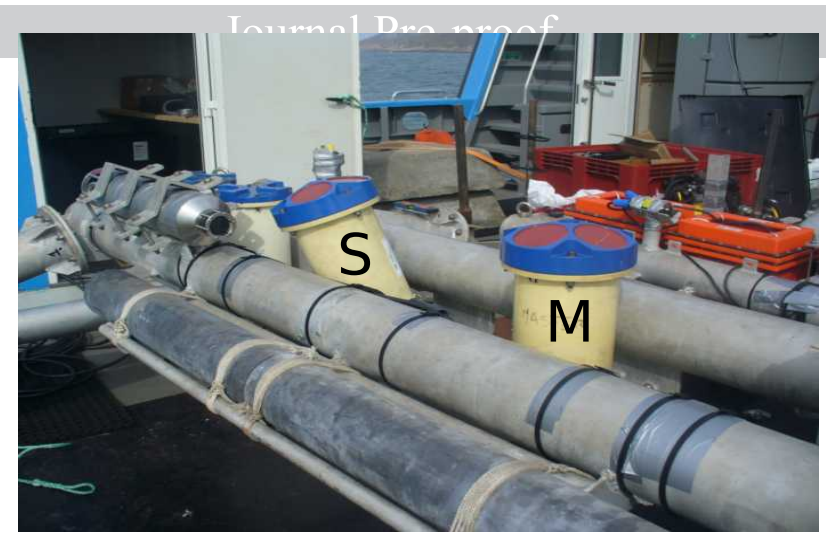

Figure 2: Master (M) and Slave (S) ADCP mounted on the frame prior the deployment.

From the wave linear theory, $S_{\zeta}(f)$ can be transformed into the energy-spectrum $S_{\boldsymbol{u}_{w}}(f)$ of the orbital velocities through a transfer function:

$$
S_{\boldsymbol{u}_{w}}(f)=\left|\frac{\sinh \left[k_{\mathrm{w}}(z+D)\right]}{\sinh \left(k_{\mathrm{w}} D\right)}\right|^{2} S_{\zeta}(f)
$$

where $k_{\mathrm{w}}$ is the radian wavenumber associated with waves, $z$ the height above the seafloor and $D$ the water depth so that $z$ $=-D$ at the seabed.

Using $S_{\boldsymbol{u}_{w}}(f)$, a direct estimation of the wave orbital velocities $\mathbf{u}_{\mathbf{w}}$ throughout the water column is given by [32]:

$$
\mathbf{u}_{\mathrm{w}}=\sqrt{\int_{0}^{2 \pi} \int_{0}^{\infty} \frac{\omega^{2}}{\sinh ^{2}\left(k_{\mathrm{w}} D\right)} S_{u_{w}} \mathrm{~d} k_{\mathrm{w}} \mathrm{d} \theta}
$$

where $\omega$ is the wave angular frequency and $\theta$, the wave propagation direction.

\subsubsection{The scale of turbulent motion}

In 1922, Lewis Richardson states that turbulent agitation involves movement over a continuum of scales ranging from the size of the flow to the scale of molecular dissipation [33]. The process is based on a cascade of energy resulting from the fragmentation of the flow into structures of scales of decreasing size. Kolmogorov refined the picture of this turbulence energy cascade and used it as a foundation of his work [21]. He distinguished three scale domains: (1); the turbulenceproduction subrange, (2); the inertial subrange, and (3); the dissipation subrange. In the inertial subrange, the assumption of local isotropy holds over a range of lengthscales associated with the velocity fluctuations and a range of lengthscales associated with eddy ${ }^{1}$ size. Note that the term "local isotropy" refers only to the small-scales turbulent motions. The inertial subrange does not take into account the very large scale (the integral lengthscale, $L$ ), where the energy is injected into the system by the external forces, nor does it include the very small scale (the Kolmogorov microscale, $\eta$ ), where the energy is dissipated into heat by viscosity. In this subrange, the energy-spectrum function $S(k)$ of the velocity is dependent on the only TKE dissipation rate $\varepsilon[22,35]$ :

$$
S(k)=C \varepsilon^{2 / 3} k^{-5 / 3}
$$

where $C$ is the universal Kolmogorov constant $(C \approx 1.5)$ and $k$, the radian wavenumber.

A second-order structure function $D_{L L}(x, r)$ at a location $x$ can be defined such that $[21,22]$ :

$$
D_{L L}(x, r)=\left\langle\left[u_{i}^{\prime}(x+r)-u_{i}^{\prime}(x)\right]^{2}\right\rangle
$$

\footnotetext{
${ }^{1}$ An eddy is to be understood as "a component of motion with a certain lengthscale, i.e. an arbitrary flow pattern characterized by size alone" [34].
} 
where the angle brackets denote a temporal average. $D_{L L}(x, r)$ is the covariance of the difference in velocity fluctuations $u_{i}^{\prime}$ between two points separated by a distance $r$. According to Kolmogorov's theory, there is a direct correspondence between the form of $S(k)$ and that of $D_{L L}(x, r)$ in the inertial subrange such that [21, 22]:

$$
D_{L L}(x, r)=C_{2} \varepsilon^{2 / 3} r^{2 / 3}
$$

where $C_{2} \approx 2.0$.

\subsubsection{ADCP estimates of the turbulence metrics}

The fluctuating velocity $\hat{u}_{i}^{\prime}$ recorded by an ADCP along the $i$ th beam is the sum of the true turbulent velocity $u_{i}^{\prime}$ and an error $n_{i}$ associated with Doppler noise such that: $\hat{u}_{i}^{\prime}=u_{i}^{\prime}+n_{i}$. The error $n_{i}$ is regularly approximated as Gaussian white noise [3,15, 36, 37] with variance $\sigma_{n_{i}}^{2}$ and with a constant spectral density $N_{i}$ given by [36]:

$$
N_{i}=\frac{\sigma_{n_{i}}^{2}}{f_{N}}
$$

where $f_{N}$ is the Nyquist frequency.

The velocity associated with the orbital motions may be observed by the ADCP, potentially affecting the energyspectrum function $S(k)$ and the second-order structure function $D_{L L}(x, r)$. Thus, a wave-induced bias in the $\varepsilon$ estimates is expected. To remove this bias, Scannell et al. [23] assumed that over a limited vertical distance around a reference location, the variation in wave orbital velocity increases as $\left(r^{2 / 3}\right)^{3}$. This hypothesis suggests that the wave orbital motions and turbulence do not interact and the associated velocity are simply additive. Hence, the second-order structure function $D_{i}(r)$ of the along-beam velocities can be given by the linear model:

$$
D_{i}(r)=\alpha_{i}+\beta_{i} r^{2 / 3}+\gamma_{i}\left(r^{2 / 3}\right)^{3}
$$

where $\alpha_{i}=2 \sigma_{n_{i}}^{2}, \beta_{i}=C_{2} \varepsilon_{i}^{2 / 3}$ and $\gamma_{i}$ is a coefficient containing the contribution to $D_{i}(r)$ as a result of the vertical gradient in the speed of the wave orbital motion. The distance $r$, between two bins, was set to be positive and was limited by the distance to the closest boundary. A least square regression of $D_{i}(r)$ versus $r^{2 / 3}$ allows for the estimation of $\varepsilon_{i}$ for each beam such that:

$$
\varepsilon_{i}=\left(\frac{\beta_{i}}{C_{2}}\right)^{3 / 2}
$$

The four $\varepsilon_{i}$ were then averaged to give the TKE dissipation rate $\varepsilon_{D}$ estimated from the second-order structure function method.

Another method allowing the estimation of the TKE dissipation rate is to use the energy spectra $S(k)$ of the along-beam velocities. Equation (3) is used to give:

$$
S_{T}(k)=C \varepsilon^{2 / 3} k^{-5 / 3}+S_{u_{w}}|\cos (\Theta)|^{2}+N_{T}
$$

where $\Theta$ is the angle between the wave propagation direction and the direction of the dominant tidal current. $S_{T}$ and $N_{T}$ are the summed wavenumber energy spectra and Doppler noise levels respectively. Using Taylor's assumption of the frozen turbulence, those quantities are given by [36]:

$$
S_{T}=\frac{\mathbf{u}}{2 \pi}\left(S_{1}+S_{2}+S_{3}+S_{4}\right)
$$




$$
N_{T}=\frac{\mathbf{u}}{2 \pi}\left(N_{1}+N_{2}+N_{3}+N_{4}\right)
$$

Therefore, the TKE dissipation rate $\varepsilon_{S}$ from the energy spectra is given by:

$$
\varepsilon_{S}=\left[C^{-1} \overline{\left(S_{T}-S_{\boldsymbol{u}_{w}}|\cos (\Theta)|^{2}-N_{T}\right) k^{5 / 3}}\right]^{3 / 2}
$$

where the overbar denotes an average over the inertial subrange and the $\mathrm{S}$ subscript allows for the method identification.

The determination of the TKE dissipation rate $\varepsilon$ from the structure function method or the spectral method allows the quantification of the integral lengthscale $(L)$ and the Kolmogorov microscale $\eta$ such that:

$$
L=\frac{\sigma_{\mathrm{u}}^{3}}{\varepsilon}
$$

and

$$
\eta=\left(\frac{v^{3}}{\varepsilon}\right)^{1 / 4}
$$

where $\sigma_{\mathbf{u}}$ is the standard deviation to the mean flow speed $\mathbf{u}$ and $v$, the kinematic viscosity of water $\left(v=1.5 \times 10^{-6}\right.$ $\mathrm{m}^{2} \mathrm{~s}^{-1}$ ). Eddies of size $(L)$ have a characteristic timescale $\tau_{L}$ whereas eddies smaller than the Kolmogorov microscale rapidly dissipate their kinetic energy by viscosity in a time roughly equal to $\tau_{\eta}$ such that [22]:

$$
\tau_{L}=L / \mathbf{u}
$$

and

$$
\tau_{\eta}=\sqrt{\frac{v}{\varepsilon}}
$$

The integral timescale, $\tau_{L}$, was used to identify the duration for which the largest eddies remain correlated wheareas the Kolmogorov timescale, $\tau_{\eta}$, was used to identify the longest time over which the microscale turbulence stays correlated $[18,22,38]$.

Turbulence intensity $(I)$ is a common metric used throughout wind and tidal industry as well as other engineering fields in order to quantify turbulence. In the present study, the three-dimensional turbulence intensity was evaluated. This required the computation of the streamwise $u$, spanwise $v$ and vertical $w$ velocity. These velocities were obtained from the product of the along-beam velocities with a transformation matrix given in [39]. The turbulence intensity $(I)$ was calculated such that:

$$
I=\frac{\sqrt{\left[\left(\sigma_{u}^{2}-\sigma_{n_{u}}^{2}\right)+\left(\sigma_{v}^{2}-\sigma_{n_{v}}^{2}\right)+\left(\sigma_{w}^{2}-\sigma_{n_{w}}^{2}\right)\right] / 3}}{\mathbf{u}}
$$

where $\sigma_{u}^{2}, \sigma_{v}^{2}$ and $\sigma_{w}^{2}$ are the variance of the mean velocity $u, v$ and $w$ respectively, and $\sigma_{n_{u}}^{2}, \sigma_{n_{v}}^{2}$ and $\sigma_{n_{w}}^{2}$ are the variance induced by Doppler noise when measuring velocities along each three spatial directions. These quantities were estimated from the energy-spectra of the streamwise, spanwise and vertical velocity (Eq. 6).

For the purpose of this paper, the turbulence metrics presented above were computed at mid-depth, which is about 15 $\mathrm{m}$ above the seabed. This elevation corresponds to the hub height of the twin-rotor of the MCT Seagen-S 1.2 MW, 16 m diameter, deployed in Strangford Narrows, UK (www.simecatlantis.com). The analysis focuses on peak tidal current velocity intervals. The time interval for averaging over these periods was chosen to be 10-min. This duration is long enough to retain the longest timescales of coherent turbulent structures in the turbulent fluctuations and short enough to remove any trend contamination from tidal currents in the turbulence time series. A total of seventy-two and seventy-three 
10-min long intervals were analyzed during flood and ebb tide respectively.

\section{Results}

\subsection{Temporal variability of mean current and wave parameters}

Variation of the mean flow speed $\mathbf{u}$ is shown in Fig. 3. The mean and maximum velocity are found to be $2 \mathrm{~m} / \mathrm{s}$ and $4.3 \mathrm{~m} / \mathrm{s}$ respectively. A characterization of the wave climatology of the site was performed. Wave parameters such as the significant wave height $H_{s}$, the peak period $T_{p}$ and the wave propagation direction were derived from ADCP measurements recorded between 27 September and 03 November, 2017 using the energy-spectra $S_{\zeta}$ of the sea surface elevation (section 2.3.1). Sea-states were globally moderate with a mean and maximum $H_{s}$ of $1.2 \mathrm{~m}$ and $4.5 \mathrm{~m}$ respectively (Fig. 3b). Peak period ranged from $3.7 \mathrm{~s}$ to $14.5 \mathrm{~s}$ with a mean value of $7.8 \mathrm{~s}$ (Fig. 3c). Fig. 4 shows the wave rose of the significant wave height and the mean wave propagation direction. Most dominant wave trains propagate from the southwestern direction. The mean wave propagation direction was found to be $250^{\circ}$ from North. This value was achieved $22 \%$ of the time. During flood tide, the dominant tidal current propagates northward ( $27^{\circ}$ from North) whereas during ebb tide, the dominant tidal current propagates southward ( $200^{\circ}$ from North).

The horizontal component of the wave orbital velocity $\mathbf{u}_{\mathbf{w}}$ (Eq. 2) was investigated. At mid-depth, the mean and maximum wave orbital velocity were found to be $0.35 \mathrm{~m} / \mathrm{s}$ and $1.15 \mathrm{~m} / \mathrm{s}$ respectively (Fig. 3a). On average, $\mathbf{u}_{\mathbf{w}}$ was found to be within $17 \%$ of the mean flow speed.

\subsection{Velocity spectra}

Energy spectra $S_{i}(f)$ of the along-beam velocities were computed during periods of peak flood and ebb velocity at three successive bins (from bin 10 to 12) and averaged to give the mean spectra at mid-depth. Hamming window intervals of 120 points with $50 \%$ overlap were used to give 18 equivalent degrees of freedom for each estimate. Velocity spectra for beam 1 are presented in Fig. 5 colored by mean flow conditions. Three distinct regions are considered: the low frequency
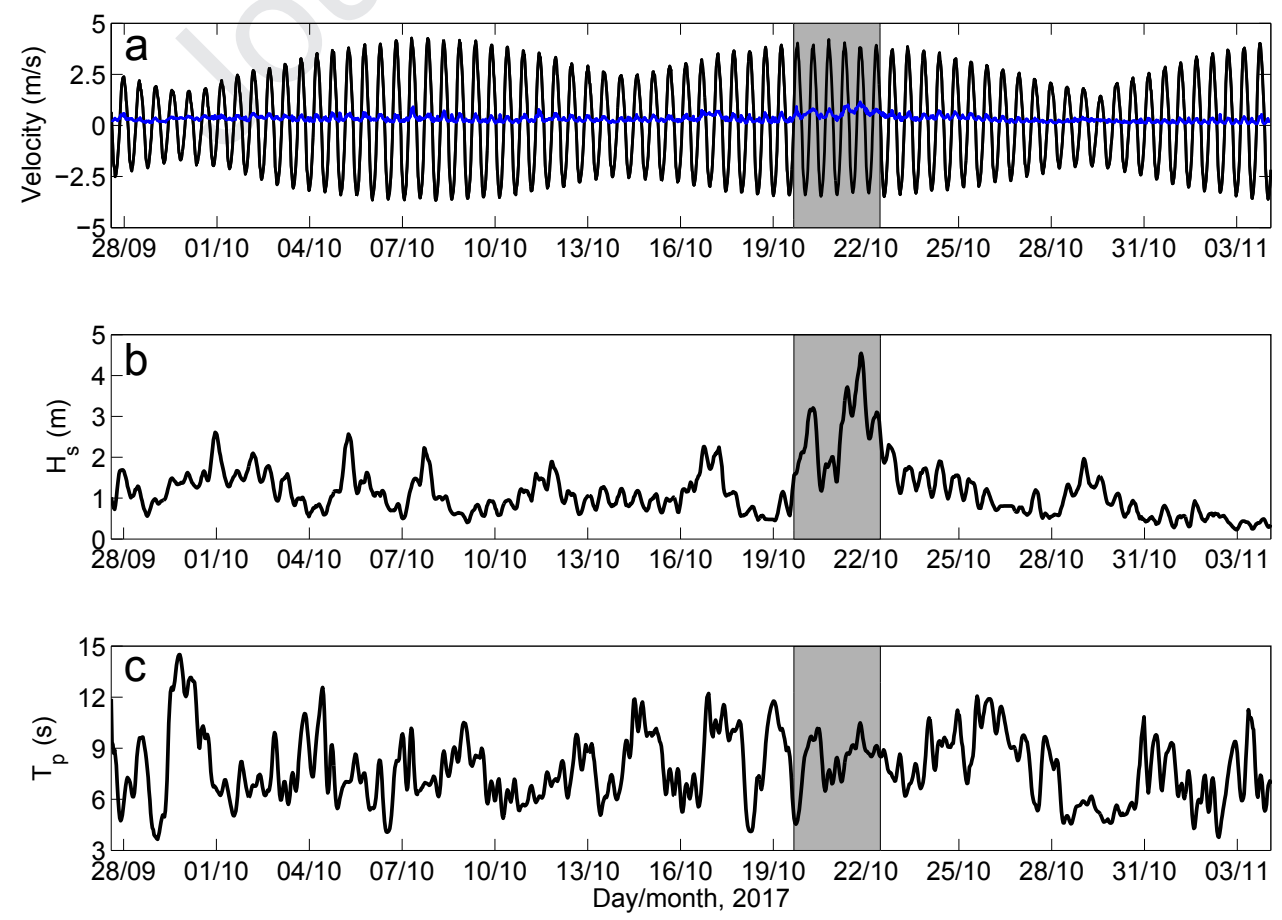

Figure 3: Time series (30-min averaged) of the flow speed (black curve) and horizontal component of the wave orbital velocity (blue curve) obtained at mid-depth (a). Time series of the significant wave height $H_{s}$ and peak period $T_{p}$ are given in (b) and (c) respectively. The gray regions show the storm period: from October 19, 16:00 to October 22, 2017, 11:00. 


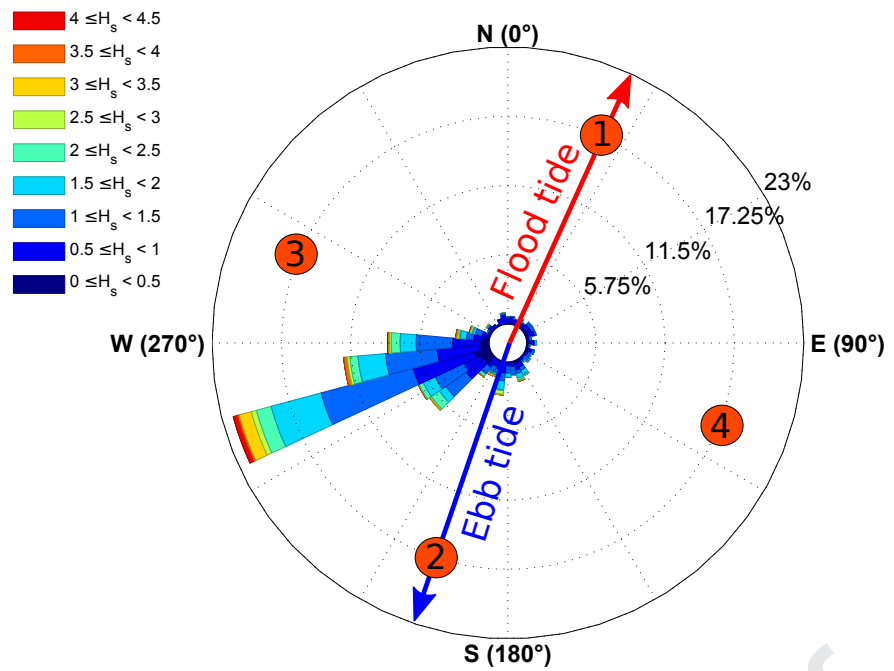

Figure 4: Wave rose of significant wave-height $H_{s}$ (color scale) and mean wave propagation direction (histograms) observed from 27 September to 03 November 2017. Occurrences of mean wave propagation directions are shown in percentage. Red and blue arrows show the direction of the streamwise tidal velocity during flood and ebb tide respectively. The circled numbers correspond to the transducer faces for the diverging beams of the ADCP.

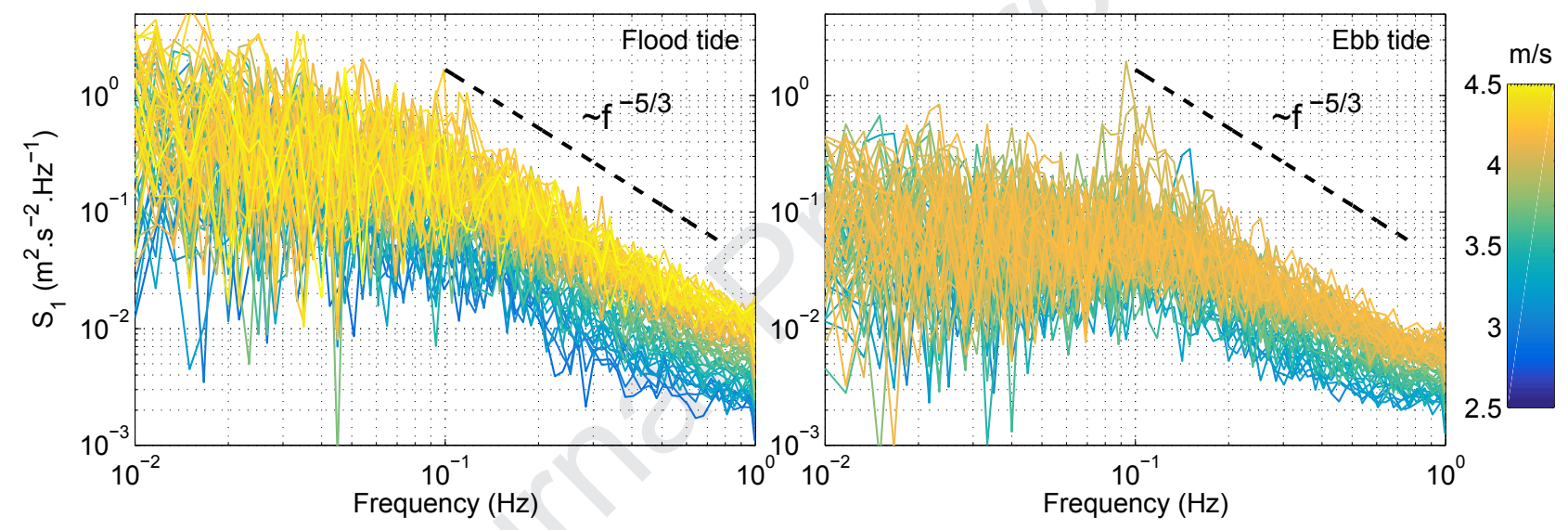

Figure 5: Energy spectra of the mid-depth velocity obtained for the beam 1 of the ADCP during peak flooding (left panel) and ebbing (right panel) tidal conditions. Color scale account for the flow speed at mid-depth. Black dashed lines show the classic spectral slope $f^{-5 / 3}$.

subrange $(f \leq 0.1 \mathrm{~Hz})$, the inertial subrange $(0.1 \mathrm{~Hz}<f<0.8 \mathrm{~Hz})$ and the high frequency subrange $(f \geq 0.8 \mathrm{~Hz})$. These three regions were also exhibited when computing the velocity spectra for the beam 2, 3 and 4 (results not shown). This allows for supporting the identification of the isotropic and anisotropic regions identified hereinafter since similar frequency domains and shape of the velocity spectra were found for each beam.

At low frequencies (i.e., the turbulence-production subrange), the large energy-containing eddies are responsible for the energy exchange between the mean flow and the turbulence. The slope of the velocity spectra, less steep than within the inertial subrange, shows the large-scale anisotropy. At midfrequencies, an isotropic region of tridimensional turbulence following the classic $f^{-5 / 3}$ energy cascade is exhibited. There, the energy is cascading down from large (i.e., lower frequencies) to small (i.e., higher frequencies) eddies. At high frequencies, the spectra are affected by the instrument inherent Doppler noise which induces a constant spectral density $N_{i}$ for each $i$ th beam. The four values of $N_{i}$ were estimated and averaged to give $\bar{N}$. Scatterplots of $\bar{N}$ as a function of flow speed during ebb and flood tide (Fig. 6, blue and red circles) were fit by a quadratic function with a very strong coefficient of determination $R^{2}$ of 0.92 and 0.94 respectively. This result demonstrates a clear dependency of $\bar{N}$ to the flow velocity squared. On average, $\bar{N}$ was found to be $5.4 \times 10^{-3}$ $\mathrm{m}^{2} \mathrm{~s}^{-2} \mathrm{~Hz}^{-1}$ during ebb tide and $8.2 \times 10^{-3} \mathrm{~m}^{2} \mathrm{~s}^{-2} \mathrm{~Hz}^{-1}$ during flood tide.

Peak wave frequency $F_{p}=1 / T_{p}$, observed during peak flooding and ebbing tidal conditions ranged from $0.05 \mathrm{~Hz}$ to 
more than $0.12 \mathrm{~Hz}$ with a mean value of $0.08 \mathrm{~Hz}$. This frequency range overlaps the turbulence-production subrange and the inertial subrange. $F_{p}$ was found $80 \%$ of the time within the low frequency subrange $(f \leq 0.1 \mathrm{~Hz})$ whereas the other $20 \%$ were found in the inertial subrange. There, the mean wave-induced energy $\overline{S_{\boldsymbol{u}_{w}}}$ varies in a wide range: from $8 \times$ $10^{-3}$ to $10^{-1} \mathrm{~m}^{2} \mathrm{~s}^{-2} \mathrm{~Hz}^{-1}$ (Fig. 6). On average $\overline{S_{\boldsymbol{u}_{w}}}$ was found to be $10.6 \times 10^{-3} \mathrm{~m}^{2} \mathrm{~s}^{-2} \mathrm{~Hz}^{-1}$ during ebb tide and $9.2 \times 10^{-3}$ $\mathrm{m}^{2} \mathrm{~s}^{-2} \mathrm{~Hz}^{-1}$ during flood tide. Moreover, the mean ratio $\overline{S_{\boldsymbol{u}_{w}}} / \bar{N}$ was found to be 2.4 and 1.7 during ebbing and flooding tidal conditions respectively. The event $\overline{S_{\boldsymbol{u}_{w}}}>\bar{N}$ has an occurrence of $52 \%$ during ebb tide and $45 \%$ during flood tide and it was only observed when the values of $H_{s}$ were higher than $2 \mathrm{~m}$.

\subsection{Structure function}

The structure function $D_{i}(r)$ of the along-beam velocities was estimated. The $r^{2 / 3}$ slope in the structure function was found within the $r$ range $[1.3 \mathrm{~m} ; 10.4 \mathrm{~m}$ ] during flood tide and [1.3 $\mathrm{m} ; 7.8 \mathrm{~m}$ ] during ebb tide (Fig. 7). The upper limit, $r_{\max }$, of these ranges was chosen to include as much of the inertial subrange as possible. Beyond $r_{\max }, D_{i}(r)$ tends toward a constant or physically meaningless high value (not shown in Fig. 7). $D_{i}(r)$ with negative slope $\left(\beta_{i}<0\right)$ were removed from the analysis resulting in a loss of $8 \%$ of the structure functions. This is 3 to 5 times lower than other studies applying the structure function (e.g., [3, 15, 26]).

Properly identifying the inertial subrange is essential for an accurate estimation of the dissipation rate and indirectly for the estimation of the integral lengthscale and the Kolmogorov microscale. Therefore, a sensitivity study of the value of $r_{\max }$ to the dissipation rate estimate $\varepsilon_{D}$ was performed through the calculation of the relative error $(e)$. Values of $\varepsilon_{D}$ derived from $r_{\max }=10.4 \mathrm{~m}$ for flooding tidal conditions and $r_{\max }=7.8 \mathrm{~m}$ for ebbing tidal conditions were used as a "reference" for the calculation of $(e)$ since they are spanning the most extended inertial subrange.

Fig. 8 depicting the evolution $\varepsilon_{D}$ as a function of $r_{\max }$ indicates that the lowest value of the dissipation rate is obtained when setting $r_{\max }$ to be equal to $10.4 \mathrm{~m}$ and $7.8 \mathrm{~m}$ on flood and ebb tide respectively. Beyond these $r_{\max }$ values, $\varepsilon_{D}$ increases significantly. As a consequence, the relative error $(e)$ reaches $25 \%$ during ebb tide and up to $50 \%$ during flood tide (Table 1). $\varepsilon_{D}$ estimates higher than $r=10.4 \mathrm{~m}$ for the flooding stage of the tide and higher than $r=7.8 \mathrm{~m}$ for the

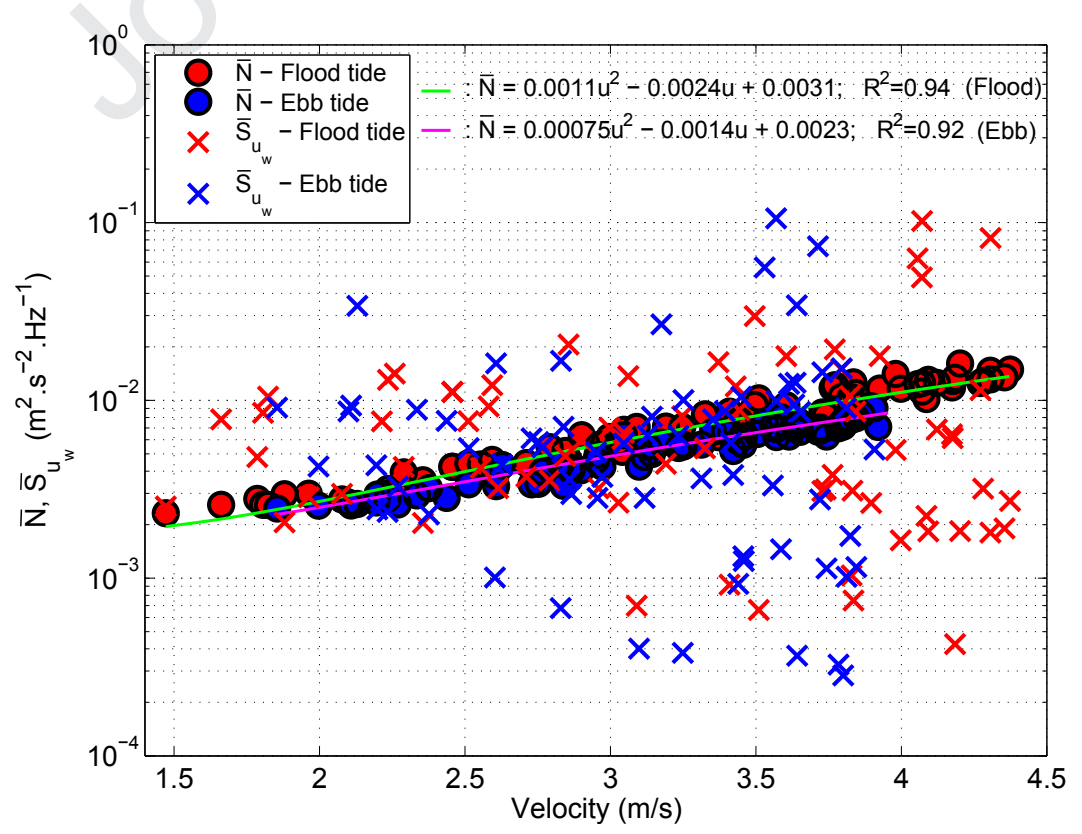

Figure 6: Mean constant spectral density $\bar{N}$ induced by Doppler noise (circles) and mean wave-induced energy $\overline{S_{\boldsymbol{u}_{w}}}$ (crosses) computed in the inertial subrange. Red and blue colors are used to identify peak flood and ebb tidal conditions respectively. Quadratic best-fit of the scatterplots of $\bar{N}$ obtained during flood and ebb tide are shown by green and magenta solid line respectively. The equation and the coefficient of determination $R^{2}$ of both quadratic regressions are also shown. 

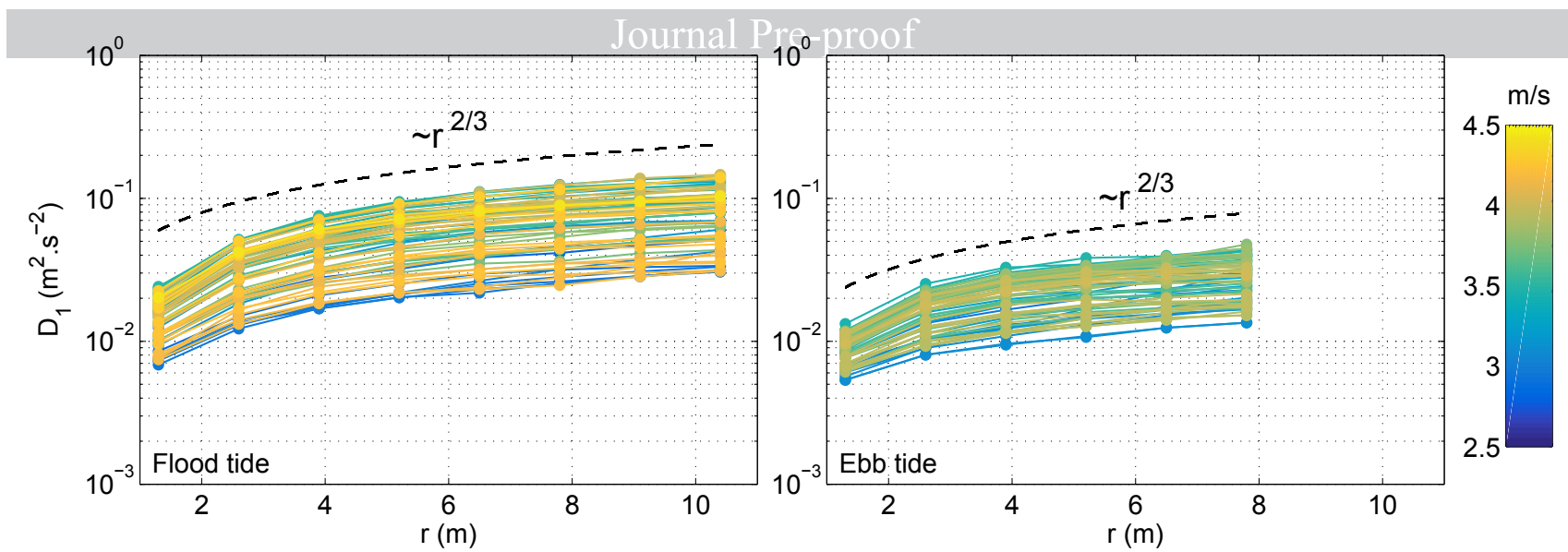

Figure 7: Structure functions obtained in the inertial subrange for the beam 1 of the ADCP during peak flooding (left panel) and ebbing (right panel) tidal conditions. Color scale account for the flow speed at mid-depth. Black dashed curves show the classic $r^{2 / 3}$ slope.

ebbing one are considered as being wrong since the slope of the structure function deviates from the classical $r^{2 / 3}$ slope (results not shown). Moreover, the lowest value of $r_{\max }(3.8 \mathrm{~m})$ gives high value of $\varepsilon_{D}$ during both flood and ebb tide with the highest relative error $(e=55.5 \%)$. This result suggests that a minimum number of $D_{i}(r)$ observations are required to properly quantify the dissipation rate. In our study, at least 4 values of $D_{i}(r)$ are required whereas 3 values were required in the study performed by Lucas et al. [40]. This means that the inertial subrange has to be extended up to $r_{\max }=5.2$ m (the fourth value of $D_{i}(r)$ ), at least, to provide valuable estimates of $\varepsilon_{D}$. During flood tide, low variations of $\varepsilon_{D}$ are exhibited for $r_{\max }$ values lying within the range [5.2 m; $10.4 \mathrm{~m}$ ]. During ebb tide, this range of low variations is smaller: [5.2 $\mathrm{m} ; 7.8 \mathrm{~m}]$. Within those ranges, $(e)$ ranges from $4 \%$ to $14 \%$.

\subsection{Turbulence metrics}

\subsubsection{Turbulence intensity and dissipation rate}

The turbulence intensity $(I)$ is a standard metric used by investigators when studying turbulent flow. It is an essential input of every commercial computational fluid dynamic (CFD) codes to simulate turbine performance in wind (e.g. TurbSim [41]) and tidal energy industry. The turbulence intensity was corrected for Doppler noise resulting in a reduction of $(I)$ estimates by $10 \%$ on average. Note that this percentage varies with flow speed. The maximum reduction of $16 \%$ was reached for velocity of $4.5 \mathrm{~m} / \mathrm{s}$. Fig. 9 shows the noise-corrected turbulence intensity variation as a function of flow speed. (I) values vary from $5 \%$ to up to $13 \%$. The turbulence intensity was found to be independent to the flow speed. Scatterplots are flattened and $(I)$ estimates vary little from the mean which are $9.8 \pm 0.9 \%$ and $7.5 \pm 0.8 \%$ for flood and ebb tide respectively.

The spectral and structure function methods were implemented to compute the dissipation rate. Estimates were corrected from the wave-induced bias $\tilde{\varepsilon}$ and the Doppler noise-induced bias $\hat{\varepsilon}$. Similar values of $\hat{\varepsilon}$ were found for both methods $\left(0.2-0.3 \times 10^{-3} \mathrm{~m}^{2} \mathrm{~s}^{-3}\right)$. In contrast, significant differences in $\tilde{\varepsilon}$ estimates were found. The dissipation rate estimates from the structure function were found to be lowly biased by the wave orbital motion. On average, $\tilde{\varepsilon_{D}}$ is $0.06 \times$ $10^{-3} \mathrm{~m}^{2} \mathrm{~s}^{-3}$ and $0.05 \times 10^{-3} \mathrm{~m}^{2} \mathrm{~s}^{-3}$ during flood and ebb tide respectively whereas the mean wave-induced bias $\tilde{\varepsilon_{S}}$, derived

\begin{tabular}{|c|c|c|c|c|c|c|c|}
\hline$r_{\max }(\mathrm{m})$ & 3.8 & 5.2 & 7.8 & 9.1 & 10.4 & 11.7 & 13.0 \\
\hline Relative error $e(\%)$ - Flood tide & 55.5 & 14 & 11 & 5.5 & 0 & 22 & 50 \\
\hline Relative error $e(\%)$ - Ebb tide & 37.5 & 4 & 0 & 25 & - & - & - \\
\hline
\end{tabular}

Table 1: Relative error $(e)$ in $\varepsilon_{D}$ estimation when using different values of $r_{\max }$ during flood (red) and ebb (blue) tide. The "reference" value of $\varepsilon_{D}$ was set to be that computed for $r_{\max }=10.4 \mathrm{~m}$ for flooding tidal conditions and $r_{\max }=7.8 \mathrm{~m}$ for ebbing tidal conditions (crosses in Fig. 8). 


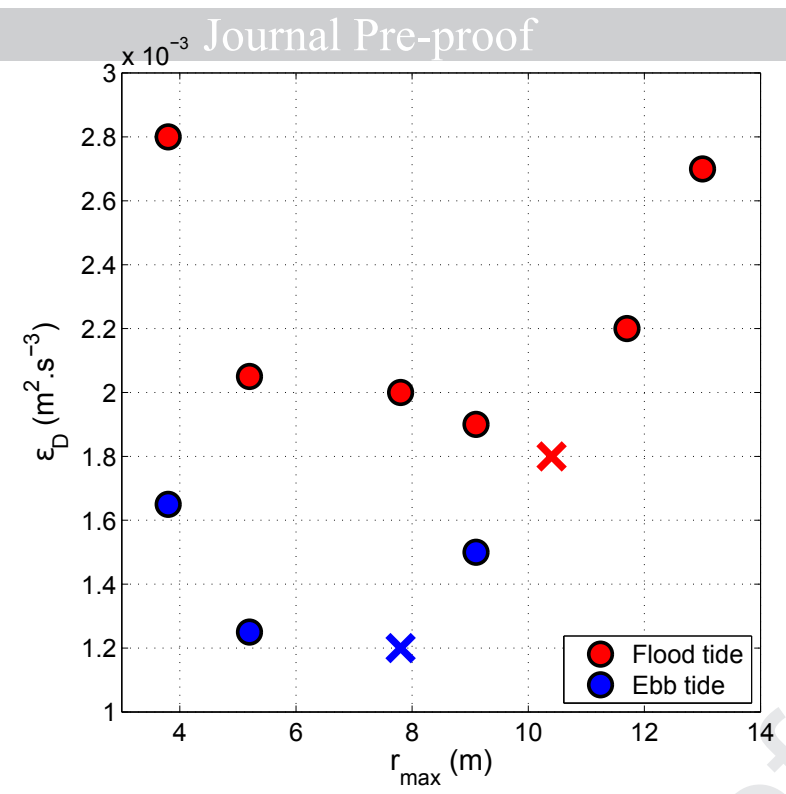

Figure 8: Estimation of the dissipation rate $\varepsilon_{D}$ from the structure function method when using different values of $r_{\text {max }}$. Crosses are used to identify the $\varepsilon_{D}$ values used hereafter, in this study. Each estimate was performed at mid-depth during peak flooding (red) and ebbing (blue) tidal conditions.

from the spectral method, is 7 times higher (Table 2).

Estimates of $\varepsilon_{S}$ and $\varepsilon_{D}$ are plotted one against the other in Fig. 10a. $\varepsilon_{S}$ is within the range $\left[6.7 \times 10^{-4} ; 4.8 \times 10^{-3}\right]$ $\mathrm{m}^{2} \mathrm{~s}^{-3}$ while $\varepsilon_{D}$ varies in a slightly wider range $\left[1.4 \times 10^{-4} ; 5.8 \times 10^{-3}\right] \mathrm{m}^{2} \mathrm{~s}^{-3}$. On average, $\varepsilon_{S}$ was found to be $1.9 \times$ $10^{-3} \mathrm{~m}^{2} \mathrm{~s}^{-3}$ during flood tide and $1.3 \times 10^{-3} \mathrm{~m}^{2} \mathrm{~s}^{-3}$ during ebb tide whereas the mean values of $\varepsilon_{D}$ are slightly lower: 1.8 $\times 10^{-3} \mathrm{~m}^{2} \mathrm{~s}^{-3}$ and $1.2 \times 10^{-3} \mathrm{~m}^{2} \mathrm{~s}^{-3}$ respectively (Table 2). The standard deviation $\Delta \varepsilon$ to the mean is twice lower when estimating the dissipation rate from the spectral method than from the structure function method (Table 2). The ratio $\varepsilon_{S} / \varepsilon_{D}$ was estimated for both flooding and ebbing tidal conditions. On average, this ratio is 1.3 and 1.4 during flood and ebb tide respectively.

Quantile-quantile plots (Q-Q plots) of the quantiles of $\varepsilon_{D}$ estimates against that of $\varepsilon_{S}$ are shown in Fig. 10b. The slope of the Q-Q plots for both flood and ebb tide is steeper than the line of perfect agreement $\left(\varepsilon_{D}=\varepsilon_{S}\right.$, black line) revealing that the distribution of $\varepsilon_{D}$ is scattered (scatter index of $77 \%$ for $\varepsilon_{D}$ and $52 \%$ for $\varepsilon_{S}$ ). The lower slope exhibits during ebb tide demonstrates a better agreement between $\varepsilon_{D}$ and $\varepsilon_{S}$ estimates during this tidal phase than during flood tide. During ebb tide, a linear relationship between $\varepsilon_{D}$ and $\varepsilon_{S}$ is exhibited when the dissipation rate is lower than $2.0 \times$ $10^{-3} \mathrm{~m}^{2} \mathrm{~s}^{-3}$. During flood tide, $\varepsilon_{D}$ and $\varepsilon_{S}$ are linearly related over a smaller interval: from $1.0 \times 10^{-3} \mathrm{~m}^{2} \mathrm{~s}^{-3}$ to $2.0 \times 10^{-3}$ $\mathrm{m}^{2} \mathrm{~s}^{-3}$. Outside these intervals, estimates of the dissipation rate from the spectral and the structure function method are not consistent. For higher values of the dissipation rate, the Q-Q plots are left-skewed for both flood and ebb tide due to few estimates derived from the spectral method. These values of $\varepsilon_{S}$ were all observed during the storm period $\overline{\left(H_{s}\right.}=3.4$ m) which occurred from October 19, 16:00 to October 22, 2017, 11:00 (gray region in Fig. 3).

\begin{tabular}{|c|c|c|c|c|c|c|}
\hline & $\varepsilon_{S}\left(\mathrm{~m}^{2} \mathrm{~s}^{-3}\right)$ & $\varepsilon_{D}\left(\mathrm{~m}^{2} \mathrm{~s}^{-3}\right)$ & $\varepsilon_{S} / \varepsilon_{D}$ & $\Delta \varepsilon_{S}\left(\mathrm{~m}^{2} \mathrm{~s}^{-3}\right)$ & $\Delta \varepsilon_{D}\left(\mathrm{~m}^{2} \mathrm{~s}^{-3}\right)$ & $\tilde{\varepsilon}_{S}\left(\mathrm{~m}^{2} \mathrm{~s}^{-3}\right)$ \\
\hline Flood tide & $1.9 \times 10^{-3}$ & $1.8 \times 10^{-3}$ & 1.3 & $0.65 \times 10^{-3}$ & $1.4 \times 10^{-3}$ & $0.5 \times 10^{-3}$ \\
\hline Ebb tide & $1.3 \times 10^{-3}$ & $1.2 \times 10^{-3}$ & 1.4 & $0.45 \times 10^{-3}$ & $0.8 \times 10^{-3}$ & $0.3 \times 10^{-3}$ \\
\hline
\end{tabular}

\begin{tabular}{|c|c|c|}
\hline$\tilde{\varepsilon_{D}}\left(\mathrm{~m}^{2} \mathrm{~s}^{-3}\right)$ & $\hat{\varepsilon_{S}}\left(\mathrm{~m}^{2} \mathrm{~s}^{-3}\right)$ & $\hat{\varepsilon_{D}}\left(\mathrm{~m}^{2} \mathrm{~s}^{-3}\right)$ \\
\hline $0.06 \times 10^{-3}$ & $0.3 \times 10^{-3}$ & $0.35 \times 10^{-3}$ \\
\hline $0.05 \times 10^{-3}$ & $0.2 \times 10^{-3}$ & $0.2 \times 10^{-3}$ \\
\hline
\end{tabular}

Table 2: Mean values and standard deviations $(\Delta)$ of the dissipation rate derived from the spectral and structure function method ( $\varepsilon_{S}$ and $\varepsilon_{D}$ respectively). The wave and Doppler noise-induced bias in the dissipation rate estimates are given by $\tilde{\varepsilon}$ and $\hat{\varepsilon}$ respectively. 


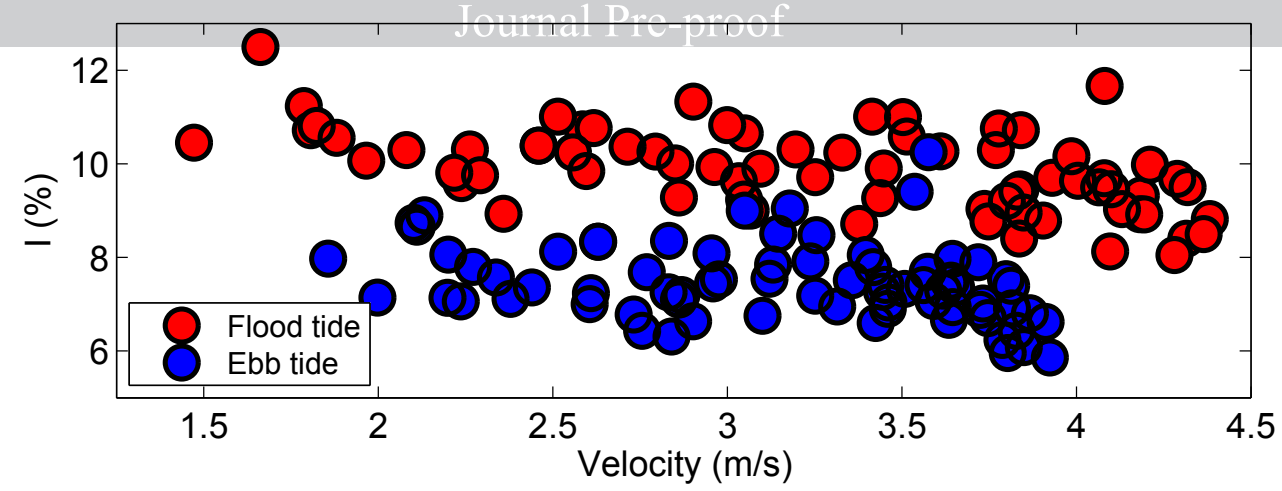

Figure 9: Turbulence intensity computed at mid-depth during peak flooding (red) and ebbing (blue) tidal conditions.
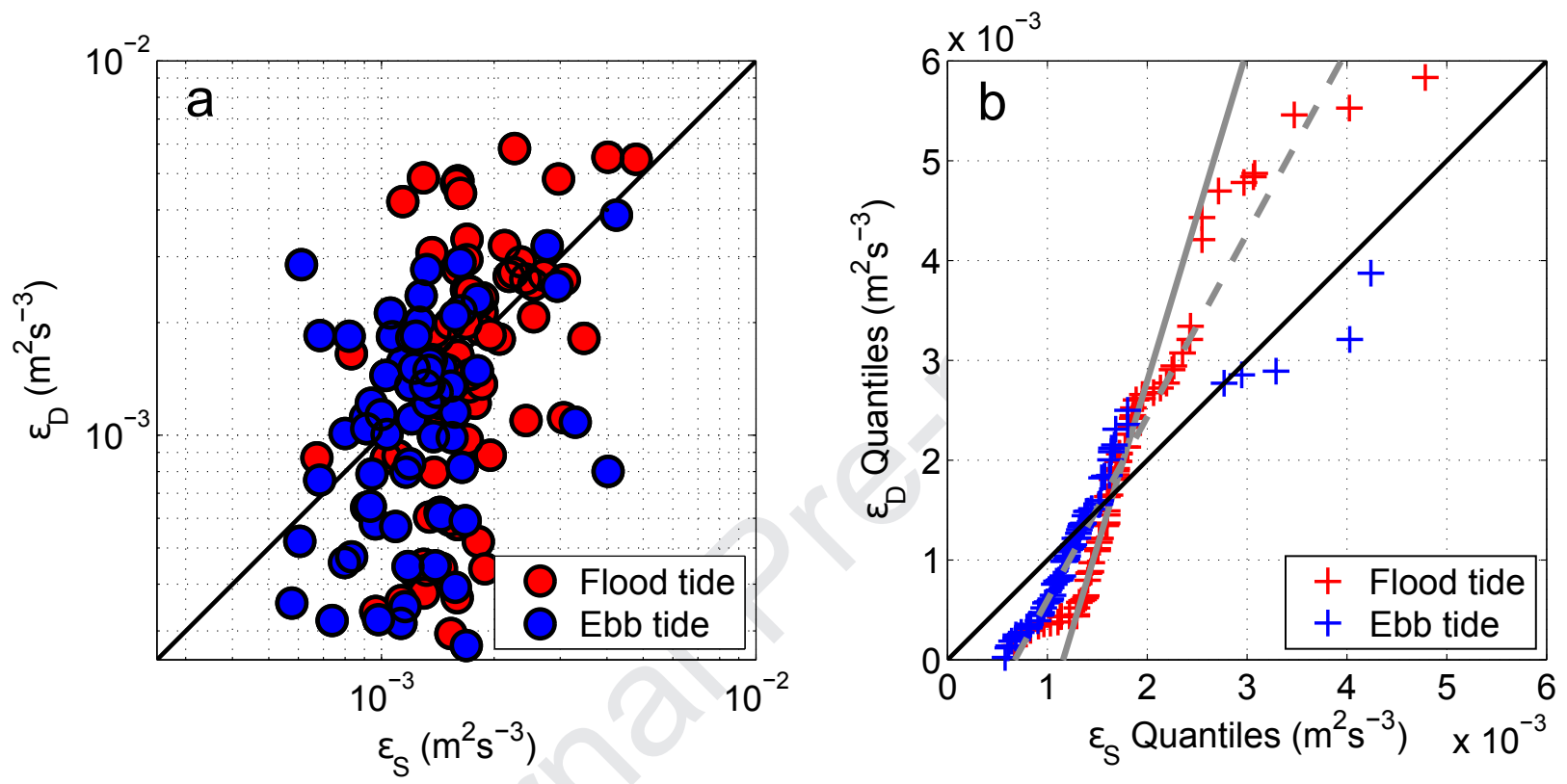

Figure 10: (a) Comparison of the dissipation rate estimates as computed from the second-order structure function $\left(\varepsilon_{D}\right)$ and the spectral method ( $\left.\varepsilon_{S}\right)$ during peak flooding (red circles) and ebbing (blue circles) tidal conditions. (b) Q-Q plots of the quantiles of $\varepsilon_{D}$ estimates against that of $\varepsilon_{S}$ during flood (red crosses) and ebb (blue crosses) tide. The straight gray line and dashed-line are the best fit of the distribution of the quantiles of $\varepsilon_{D}$ estimates against that of $\varepsilon_{S}$ estimates for flooding and ebbing tidal conditions respectively. For both panel, the black line indicates perfect agreement $\left(\varepsilon_{D}=\varepsilon_{S}\right)$.

\subsubsection{Turbulence lengthscales and timescales}

The dissipation rate allows for the estimation of two lengthscales of the turbulence: the integral lengthscale $(L)$ and the Kolmogorov microscale $\eta$. Since $(L)$ is related to $\varepsilon^{-1}$ (Eq. 13), even small difference in the dissipation rate estimates can lead to substantial difference of the integral lengthscale. Although the dissipation rate estimated from the spectral method was found to be slightly higher than that from the structure function method, a significant difference in $(L)$ estimates is expected depending on the method.

Fig. 11 shows that $(L)$ increases with the flow speed. Maximum value of $(L)$ is $150 \mathrm{~m}$ for both methods. The mean integral scale $\left(L_{D}\right)$ derived from the structure function method was found to be around $80 \mathrm{~m}$ whereas that derived from the spectral method, $\left(L_{S}\right)$, is around $60 \mathrm{~m}$ (Table 3). $\left(L_{D}\right)$ and $\left(L_{S}\right)$ were found to be slightly higher during flood tide than during ebb tide. This difference is due to a wider velocity range during the flood phase of the tide than during the ebb one. Integral lengthscale values estimated from the structure function method are very scattered throughout the velocity range (Fig. 11a). Similar flow speed (e.g., $3.5 \mathrm{~m} / \mathrm{s}$ ) can exhibit a wide range of ( $L$ ) values (from 50 to $150 \mathrm{~m}$ ). Linear regressions of $(L)$ estimates as a function of flow speed exhibited very low coefficients of determination $\left(R^{2} \sim 0.2\right)$. In contrast, the integral lengthscale derived from the spectral method exhibits a strong linear relationship between $(L)$ and the flow speed for both flood and ebb tide (Fig. 11b). The coefficient of determination $R^{2}$ of the linear regression was found to be 0.65 
during flood tide and 0.57 during ebb tide.

Joumal Pre-proof

In addition, $L_{u}, L_{v}$ and $L_{w}$ being respectively the integral lengthscale computed in the streamwise, spanwise and vertical direction were estimated. The mean ratio $L_{u} / L_{v}, L_{u} / L_{w}$ and $L_{v} / L_{w}$ were found to be $1.3,47.4$ and 37.3 respectively, indicating a clear two-dimensional (i.e., anisotropic) turbulence for the large-scale motion. Although significant differences between the integral lengthscale derived from the structure function method and that derived from the spectral method were observed, similar values of the Kolmogorov microscale $\eta$ estimated from both methods were found. On average, $\eta$ was found to be $2.3 \times 10^{-4} \mathrm{~m}$ (Table 3 ).

Estimates of the integral timescale, $\tau_{L}$ (Eq. 15), derived from the spectral method show that the largest eddies remain correlated for less than $20 \mathrm{~s}$ while $\tau_{L}$ computed from the structure function method are higher, typically $30 \mathrm{~s}$ (Table 3 ). The largest time, $\tau_{\eta}$ (Eq. 16), over which the turbulence stays correlated was also calculated for both methods. On average, $\tau_{\eta_{S}}$ and $\tau_{\eta_{D}}$ were found to be around $4.0 \times 10^{-2}$ s (Table 3$)$.

\section{Discussion}

A key step in progressing towards commercial realization of TEC array in highly energetic tidal channels is a detailed understanding of the fluid velocities surrounding turbines with a specific emphasize on turbulent fluctuations. These fluctuations are known to reduce turbine performance (e.g., [8, 42]) and they are likely to cause premature material fatigue decreasing the life expectancy of a turbine. Although numerous studies provided realistic assessment of the local hydrodynamics and the tidal stream potential (e.g. [28, 43, 44, 45, 46]) in Alderney Race, no study focusing on turbulence characterization has been reported. In order to provide designers with realistic turbulence conditions at this wave-exposed site, it is critical to properly filter the wave-induced turbulence when estimating turbulence metrics.
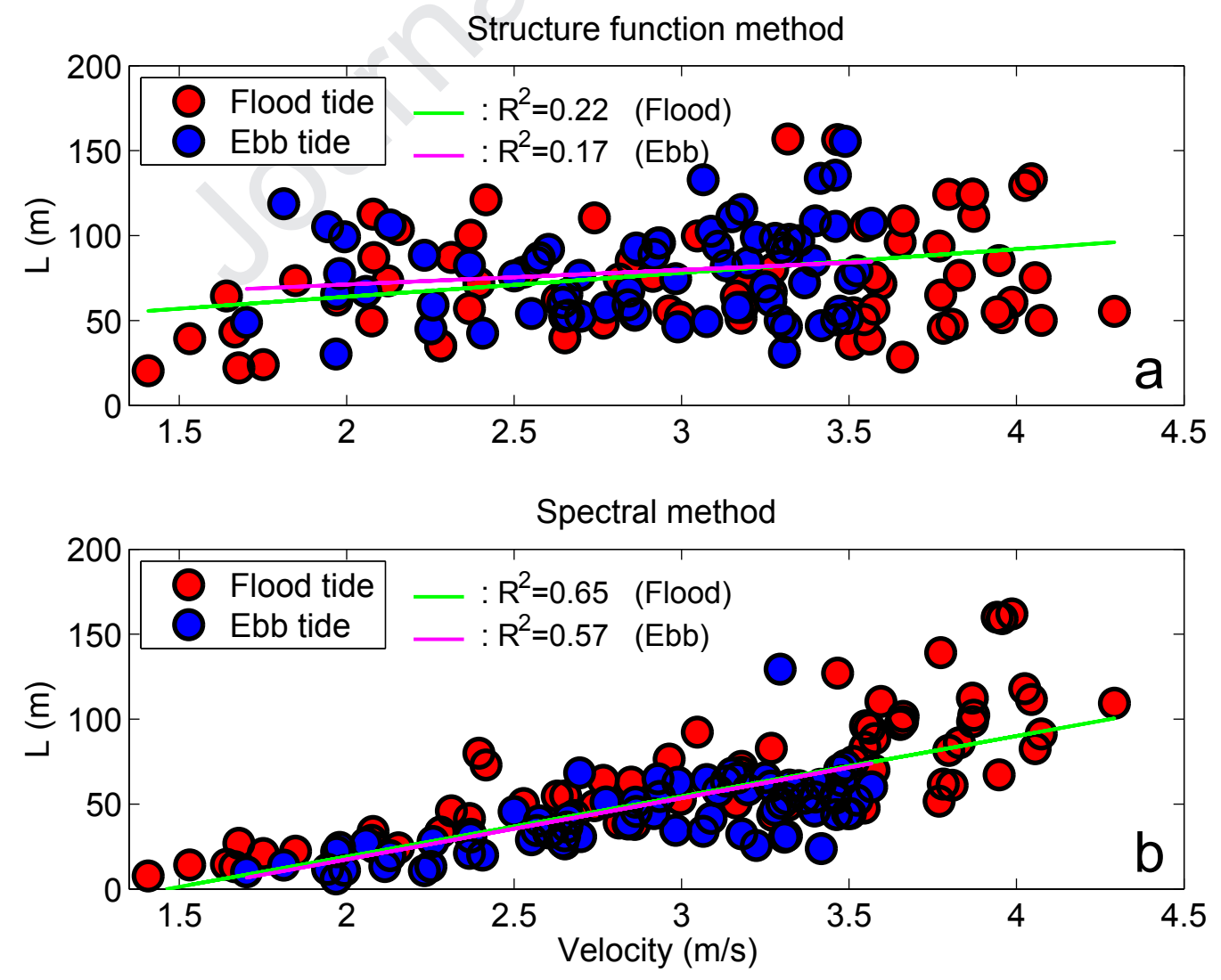

Figure 11: Integral lengthscale $(L)$ computed at mid-depth during peak flooding (red) and ebbing (blue) tidal conditions from the structure function method (a) and the spectral method (b). Linear best-fit with the coefficient of determination $R^{2}$ of the scatterplots obtained during flood and ebb tide are shown by green and magenta solid line respectively. 


\begin{tabular}{|c|c|c|c|c|c|c|c|c|}
\hline & $\eta_{S}(\mathrm{~m})$ & $\eta_{D}(\mathrm{~m})$ & $L_{S}(\mathrm{~m})$ & $L_{D}(\mathrm{~m})$ & $\tau_{\eta_{S}}(\mathrm{~s})$ & $\tau_{\eta_{D}}(\mathrm{~s})$ & $\tau_{L_{S}}(\mathrm{~s})$ & $\tau_{L_{D}}(\mathrm{~s})$ \\
\hline Flood tide & $2.0 \times 10^{-4}$ & $2.3 \times 10^{-4}$ & 66.8 & 81.5 & $3.0 \times 10^{-2}$ & $3.6 \times 10^{-2}$ & 19.1 & 32.9 \\
\hline Ebb tide & $2.3 \times 10^{-4}$ & $2.6 \times 10^{-4}$ & 57.2 & 80.7 & $4.1 \times 10^{-2}$ & $4.7 \times 10^{-2}$ & 17.6 & 29.6 \\
\hline
\end{tabular}

Table 3: Lengthscales $(\eta,(L))$ and timescales $\left(\tau_{\eta}, \tau_{L}\right)$ of the turbulence computed at mid-depth during peak flooding and ebbing tidal conditions from the spectral method (subscript $S$ ) and the structure function method (subscript $D$ ).

In this paper, we present the first study on ambient turbulence characterization in Alderney Race. Particular attention is paid on removing wave and Doppler noise-induced bias in the estimation of turbulence metrics. Velocity measurements recorded by an upward-looking ADCP were used to provide estimates of the turbulent lengthscales and timescales at mid-depth during peak flooding and ebbing tidal conditions.

The turbulence intensity $(I)$ was found to be up to $10 \%$ on average with maximum values reached during flood tide. This value is higher than that estimated by MacEnri et al. [42] $(I \sim 7 \%)$ in Strangford Narrows, UK, at similar height from the seabed and similar tidal conditions. Our higher values of $(I)$ are likely due to higher water depth at our study site (31 $\mathrm{m})$ than that of Strangford Narrows $(24 \mathrm{~m})$. This result suggests that turbulence intensity may be governed by bathymetry features. Thus, it is expected that the turbulence intensity at a given depth may be varying significantly from one site to another in Alderney Race. High variability in $(I)$ estimates at a single geographical site has been demonstrated by Gooch et al. [47] who pointed out the evidence of strong spatial variations of the turbulent intensity at a given location in Puget Sound, US.

Our results show that removing the Doppler-noise when estimating the turbulence intensity reduces the error by $10 \%$ on average. This result is of prime important since it demonstrates that falling to account for Doppler-noise when estimating ( $I$ ) might lead to over-engineering of TEC and increasing cost. Overestimated values of $(I)$ might also lead to an inappropriate predictability of tidal-stream power generated by a tidal turbine. On the former, Lewis et al. [9] exhibited a strong linear relationship between power variability and turbulence intensity.

The dissipation rate was estimated from two methods: the spectral method and the structure function method given respectively $\varepsilon_{S}$ and $\varepsilon_{D}$. It is a turbulent metric routinely estimated in marine environment since it has the advantage of capturing a multiscale process in a single scalar value [19, 48, 49]. A close agreement in the dissipation rate estimates between the two independent methods was found with the tendency that $\varepsilon_{S}>\varepsilon_{D}$. Similar tendency was found from fourbeam ADCPs measurements performed in the northern end of Grand Passage, Canada [36] and from five-beam ADCP measurements performed at Admiralty Inlet and Rich Passage, in Puget Sound, US [3].

The present study confirms that both waves and Doppler noise introduce bias in the dissipation rate estimates. Similar Doppler noise-induced bias $\hat{\varepsilon}$ were found when estimating the dissipation rate from the spectral or the structure function method. The spectral method was found to be very sensitive to waves whereas the structure function method exhibits low wave-induced bias $\tilde{\varepsilon}$, typically $10^{-5} \mathrm{~m}^{2} \mathrm{~s}^{-3}$. The wave-induced bias derived from the structure function method was estimated regarding the Scannell's hypothesis in which wave orbital motions and turbulence do not interact and the associated velocity are simply additive [23]. Our low values of $\tilde{\varepsilon}$ suggest that this hypothesis might not be well suited for shallow water environment strongly exposed to swell such as Alderney Race, where waves are breaking. Note that the Scannell's hypothesis has been initially tested with ADCPs measurements performed in the Celtic Sea where depth is up to $150 \mathrm{~m}$ which is 5 times higher than the depth at our measurement site. Thus, it is likely that waves in both sites are very different. The validity of the Scannell's hypothesis at our site is thus questionable.

The removal of $\hat{\varepsilon}$ and $\tilde{\varepsilon}$ allowed for a significant refining in $(L)$ estimates derived from the spectral and structure function method of $35 \%$ and $20 \%$ respectively. The integral lengthscale estimated from the spectral method and that derived from the structure function method were found to be $60 \mathrm{~m}$ and $80 \mathrm{~m}$ respectively. These results show that the 
most energetic eddies in Alderney Race are about 2-3 times the local water depth. The presence of these anisotropic, bidimensional eddies is consistent with a transition from highly energetic eddies at larger scales to an isotropic cascade of energy at smaller scale which are limited by either water depth or stratification. These large size turbulent eddies contain the largest proportion of turbulent energy, and are therefore likely to have the greatest effect on turbines performance. Recently, a study focusing on the assessment of the performance of a Darrieus type turbine operating in real sea conditions demonstrated that the strongest impact of turbulence on power generation by the tidal turbine occurred when the size of the most energetic eddies attains and exceeds the turbine size [8]. The authors show that large size turbulent eddies exert periodic loads on the blades, strongly affect torque and cause power pulsations.

The distribution of $(L)$ estimates derived from the spectral method as a function of flow speed was fit by a linear regression with a relatively good coefficient of determination $R^{2}$ (up to 0.65 ). In contrast, the distribution of $(L)$ estimates computed from the structure function method was found to be very scattered. This result as well as the fact that the standard deviation of $\varepsilon$ derived from the spectral method is twice lower than that derived from the structure function method suggest that the spectral method is more robust for the characterization of the integral lengthscale and the dissipation rate.

However, the application of the spectral method has shown some limitations, especially when computing the Q-Q plot of the dissipation rate $\varepsilon_{D}$ estimates against that of $\varepsilon_{S}$. The Q-Q plot exhibited left-skewed distributions caused by higher values of $\varepsilon_{S}$. These estimates were obtained during the storm period which occurred from October 19, 16:00 to October 22, 2017, 11:00. This period was characterized by extreme waves with values of $H_{s}$ more than twice that the mean $H_{s}$ calculated over the 38-day period of ADCP deployment. This result reveals that the wave-induced bias $\tilde{\varepsilon}$ at mid-depth is not correctly quantified during extreme conditions. Since the speed of wave orbital motions is higher near the sea surface, it is likely that this limitation is amplified when characterizing the dissipation rate upper in the water column.

At mid-depth and for events with significant wave height $H_{s}>2 \mathrm{~m}$, values of the mean wave-induced energy $\overline{S_{\boldsymbol{u}_{w}}}$ averaged over the inertial subrange were found to be systematically higher than that of the mean constant spectral density $\bar{N}$ induced by Doppler noise. Moreover, these values of $\overline{S_{\boldsymbol{u}_{\boldsymbol{w}}}}$ were found to be increasing with increasing flow speed revealing a clear wave-current interaction. The event $H_{s}>2 \mathrm{~m}$ is not an isolated case since it was found $16 \%$ of the time. This result highlights the necessity of performing wave climatology prior any turbine deployment, especially at tidal energy sites where wave motions have significant forcing effects on the system such as that of Alderney Race.

Recently, Tatum et al. [50] performed a study focused on the wave-current interaction effects on loading characteristics. From a fluid structural interaction modeling, the authors have provided insight into the reaction of a three bladed horizontal axis tidal turbine to a simple uniform velocity. This study exhibited clear fluctuations in the loading on the individual blade leading fluctuation in the deflection of the blades during their rotation. These fluctuations were shown to cause a pulsing in the thrust transferred to the drive shaft, as well as a resultant bending moment. As a consequence, it is likely that these fluctuations lead to increased fatigue on components of the turbines, especially the blades, and thus reducing the life expectancy of the machine.

\section{Conclusions}

In this study, the first characterization of ambient turbulence in Alderney Race is presented. Velocity measurements collected by an upward-looking ADCP were used to assess turbulence metrics in this highly energetic area. Three clear findings are made in this study. (i) - Removal of wave and Doppler noise-induced bias when estimating the dissipation rate and, therefore, the integral lengthscale are shown to be a crucial step in turbulence quantification. It allowed for a significant refining in $(L)$ estimates derived from the spectral and structure function methods of $35 \%$ and $20 \%$ respec- 
tively. We believe that failing to account for wave and Doppler noise when characterizing turbulence would result in unnecessarily high factors of safety (and associated costs) and thus, jeopardize the objective of reduction of the LCoE. (ii) - The method of removing wave-bias in the structure function may not be useful for tidal-stream energy sites, and instead the spectral method is likely more suitable. However, the spectral method has shown some limitations during extreme waves events. (iii) - Doppler noise must be considered when estimating turbulence intensity ( $I$ ), a key parameter in almost all engineering methods. Considering Doppler noise will lead to reduce $(I)$ to much lower levels than reported by other authors at TEC sites.

The turbulence measurements presented in this paper would benefit to shelf sea circulation models by improving their ability in reconstructing the flow dynamics of regions exposed to wind-generated ocean waves. They will also benefit to tidal energy development and represent an important step in the development of robust design tools that will improve the survivability, reliability, and performance of tidal turbines. The present study will provide modelers and tidal turbines designers with turbulence dataset allowing them to conduct comprehensive studies on fatigue-induced hydrodynamics loads on tidal turbines through the use of computational fluid dynamics codes or stochastic flow simulation tools such as the TIDAL version of TurbSim [41].

Our recommendation to the community of engineers involved in tidal energy conversion projects is hence the following: because the turbulence and wave climate are site specific, in situ velocity measurements as well as a wave climatology are required prior any turbine deployment. A comprehensive assessment of both turbulence metrics and wave parameters will assist the engineers in obtaining more accurate performance and loading predictions. These results can allow them to select appropriate material components and incorporate some deformation capability of the different components of their turbines in order to mitigate some of the stress distribution through key structural points. 
This work benefited from funding support from France Énergies Marines and the French Government, operated by the National Research Agency under the Investments for the Future program: Reference ANR-10-IEED-0006-11. The study represents a contribution to the THYMOTE (Tidal turbulence: modeling, field observations and tank experiments) project of the above program. The skill and experience of the skipper and the crew of the R/V Penzer during the fieldwork are appreciated and acknowledged.

\section{References}

[1] M. Lewis, S. P. Neill, P. Robins, M. R. Hashemi, and S. Ward, "Characteristics of the velocity profile at tidal-stream energy sites," Renewable Energy, vol. 114, pp. 258-272, 2017.

[2] T. Leroux, N. Osbourne, and D. Groulx, "Numerical study into horizontal tidal turbine wake velocity deficit: Quasi-steady state and transient approaches," Ocean Engineering, vol. 181, pp. 240-251, 2019.

[3] M. Guerra and J. Thomson, "Turbulence Measurements from Five-Beam Acoustic Doppler Current Profilers," Journal of Atmospheric and Oceanic Technology, vol. 34, no. 6, pp. 1267-1284, 2017.

[4] M. Thiébaut and A. Sentchev, "Tidal stream resource assessment in the Dover Strait (eastern English Channel)," International Journal of Marine Energy, vol. 16, pp. 262-278, 2016.

[5] — " "Asymmetry of tidal currents off the W. Brittany coast and assessment of tidal energy resource around the Ushant Island," Renewable Energy, vol. 105, pp. 735-747, 2017.

[6] P. Liu and B. Veitch, "Design and optimization for strength and integrity of tidal turbine rotor blades," Energy, vol. 46, no. 1, pp. 393-404, 2012.

[7] I. A. Milne, A. H. Day, R. N. Sharma, and R. G. J. Flay, "Blade loading on tidal turbines for uniform unsteady flow," Renewable Energy, vol. 77, pp. 338-350, 2015.

[8] A. Sentchev, M. Thiébaut, and F. G. Schmitt, "Impact of turbulence on power production by a free-stream tidal turbine in real sea conditions," Renewable Energy, vol. 147, pp. 1932-1940, 2019.

[9] M. Lewis, J. McNaughton, C. Márquez-Dominguez, G. Todeschini, M. Togneri, I. Masters, M. Allmark, T. Stallard, S. Neill, and A. Goward-Brown, "Power variability of tidal-stream energy and implications for electricity supply," Energy, vol. 183, pp. 1061-1074, 2019.

[10] G. Pinon, P. Mycek, G. Germain, and E. Rivoalen, "Numerical simulation of the wake of marine current turbines with a particle method," Renewable Energy, vol. 46, pp. 111-126, 2012.

[11] M. J. Churchfield, Y. Li, and P. J. Moriarty, "A large-eddy simulation study of wake propagation and power production in an array of tidal-current turbines," Phil. Trans. R. Soc. A, vol. 371, no. 1985, p. 20120421, 2013.

[12] L. P. Chamorro, C. Hill, S. Morton, C. Ellis, R. E. A. Arndt, and F. Sotiropoulos, "On the interaction between a turbulent open channel flow and an axial-flow turbine," Journal of Fluid Mechanics, vol. 716, pp. 658-670, 2013.

[13] P. Mycek, B. Gaurier, G. Germain, G. Pinon, and E. Rivoalen, "Experimental study of the turbulence intensity effects on marine current turbines behaviour. Part I: One single turbine," Renewable Energy, vol. 66, pp. 729-746, 2014.

[14] M. Togneri, M. Lewis, S. Neill, and I. Masters, "Comparison of ADCP observations and 3d model simulations of turbulence at a tidal energy site," Renewable Energy, vol. 114, pp. 273-282, 2017.

[15] J. Thomson, B. Polagye, V. Durgesh, and M. C. Richmond, "Measurements of turbulence at two tidal energy sites in Puget Sound, WA," Oceanic Engineering, IEEE Journal of Oceanic Engineering, vol. 37, no. 3, pp. 363-374, 2012.

[16] J.-F. Filipot, M. Prevosto, C. Maisondieu, M. Le Boulluec, and J. Thomson, "Wave and turbulence measurements at a tidal energy site." Proceedings of a meeting held 2-6 March 2015, St. Petersburg, Florida, USA. IEEE Catalog Number:CFP15CWT-POD, 2015, pp. 198-206.

[17] A. Pieterse, J.-F. Filipot, C. Maisondieu, L. Kilcher, and N. Chaplain, "Coupled ADCP measurements for tidal turbulence characterization.” Proceedings of the 12th European Wave and Tidal Energy Conference, Cork, Ireland, 2017, 2017, pp. 1-8.

[18] I. A. Milne, R. N. Sharma, R. G. J. Flay, and S. Bickerton, "Characteristics of the turbulence in the flow at a tidal stream power site," Philosophical Transactions of the Royal Society of London A: Mathematical, Physical and Engineering Sciences, vol. 371, no. 1985, 2013. 
[19] P. J. Wiles, T. P. Rippeth, J. H. Simpson, and P. J. Hendricks, "A novel technique for measuring the rate of turbulent dissipation in the marine environment," Geophysical Research Letters, vol. 33, no. 21, 2006.

[20] J. H. Simpson, N. S. Lucas, B. Powell, and S. C. Maberly, "Dissipation and mixing during the onset of stratification in a temperate lake, Windermere," Limnology and Oceanography, vol. 60, no. 1, pp. 29-41, 2015.

[21] A. N. Kolmogorov, "The local structure of turbulence in incompressible viscous fluid for very large Reynolds numbers," in Dokl. Akad. Nauk SSSR, vol. 30. JSTOR, 1941, pp. 301-305.

[22] S. B. Pope, Turbulent flows. Cambridge University Press, 2000.

[23] B. D. Scannell, T. P. Rippeth, J. H. Simpson, J. A. Polton, and J. E. Hopkins, "Correcting surface wave bias in structure function estimates of turbulent kinetic energy dissipation rate," Journal of Atmospheric and Oceanic Technology, vol. 34, no. 10, pp. 2257-2273, 2017.

[24] M. Togneri, D. Jones, S. Neill, M. Lewis, S. Ward, M. Piano, and I. Masters, "Comparison of 4-and 5-beam acoustic Doppler current profiler configurations for measurement of turbulent kinetic energy,” Energy Procedia, vol. 125, pp. 260-267, 2017.

[25] M. J. Lewis, S. P. Neill, M. R. Hashemi, and M. Reza, "Realistic wave conditions and their influence on quantifying the tidal stream energy resource," Applied Energy, vol. 136, pp. 495-508, 2014.

[26] J. M. McMillan, A. E. Hay, R. G. Lueck, and F. Wolk, "Rates of dissipation of turbulent kinetic energy in a high Reynolds number tidal channel," Journal of Atmospheric and Oceanic Technology, vol. 33, no. 4, pp. 817-837, 2016.

[27] E. Williams and J. H. Simpson, "Uncertainties in estimates of Reynolds stress and TKE production rate using the ADCP variance method," Journal of Atmospheric and Oceanic Technology, vol. 21, no. 2, pp. 347-357, 2004.

[28] M. Thiébaut, A. Sentchev, and P. Bailly du Bois, "Merging velocity measurements and modeling to improve understanding of tidal stream resource in Alderney Race,” Energy, vol. 178, pp. 460-470, 2019.

[29] B. Vermeulen, A. J. F. Hoitink, and M. G. Sassi, "Coupled ADCPs can yield complete Reynolds stress tensor profiles in geophysical surface flows," Geophysical Research Letters, vol. 38, no. 6, 2011.

[30] R. D. Instruments, “Workhorse Acoustic Doppler Current Profiler Technical Manual,” 2005.

[31] D. G. Goring and V. I. Nikora, "Despiking acoustic Doppler velocimeter data," Journal of Hydraulic Engineering, vol. 128, no. 1, pp. 117-126, 2002.

[32] H. L. Tolman, "User manual and system documentation of WAVEWATCH III TM version 3.14," Technical note, MMAB Contribution, vol. 276, p. 220, 2009.

[33] L. F. Richardson, Weather prediction by numerical process. Cambridge University Press, 1922.

[34] G. K. Batchelor, The theory of homogeneous turbulence. Cambridge University Press, 1953.

[35] U. Frish, The legacy of A.N. Kolmogorov. Cambridge University Press, 1995.

[36] J. M. McMillan and A. E. Hay, "Spectral and structure function estimates of turbulence dissipation rates in a high-flow tidal channel using broadband ADCPs," Journal of Atmospheric and Oceanic Technology, vol. 34, no. 1, pp. 5-20, 2017.

[37] V. Durgesh, J. Thomson, M. C. Richmond, and B. L. Polagye, "Noise correction of turbulent spectra obtained from acoustic doppler velocimeters," Flow Measurement and Instrumentation, vol. 37, pp. 29-41, 2014.

[38] K. McCaffrey, B. Fox-Kemper, P. E. Hamlington, and J. Thomson, "Characterization of turbulence anisotropy, coherence, and intermittency at a prospective tidal energy site: Observational data analysis," Renewable Energy, vol. 76, pp. 441-453, 2015.

[39] A. C. Transformation, "Formulas and Calculations," Teledyne RD Instruments, 2010.

[40] N. S. Lucas, J. H. Simpson, T. P. Rippeth, and C. P. Old, "Measuring turbulent dissipation using a tethered ADCP," Journal of Atmospheric and Oceanic Technology, vol. 31, no. 8, pp. 1826-1837, 2014.

[41] J. Jonkman and L. Kilcher, “TurbSim User's Guide: Version 1.06.00, National Renewable Energy Laboratory,” Tech. Rep., 2012.

[42] J. MacEnri, M. Reed, and T. Thiringer, "Influence of tidal parameters on SeaGen flicker performance," Philosophical Transactions of the Royal Society of London A: Mathematical, Physical and Engineering Sciences, vol. 371, no. 1985, p. $20120247,2013$.

[43] D. S. Coles, L. S. Blunden, and A. S. Bahaj, "Assessment of the energy extraction potential at tidal sites around the Channel Islands," Energy, vol. 124, pp. 171-186, 2017.

[44] P. Bailly du Bois, F. Dumas, L. Solier, and C. Voiseux, "In-situ database toolbox for short-term dispersion model validation in macro-tidal seas, application for 2d-model," Continental Shelf Research, vol. 36, pp. 63-82, 2012.

[45] J. Thiébot, P. Bailly du Bois, and S. Guillou, "Numerical modeling of the effect of tidal stream turbines on the hydrodynamics and the sediment transport - Application to the Alderney Race (Raz Blanchard), France," Renewable Energy, vol. 75, pp. 356-365, 2015. 
[46] N. Guillou, S. P. Neill, and P. E. Robins, "Characterising the tidal stream power resource around France using a high-resolution harmonic database," Renewable Energy, 2018.

[47] S. Gooch, J. Thomson, B. Polagye, and D. Meggitt, Site characterization for tidal power. OCEANS 2009, MTS/IEEE BiloxiMarine Technology for Our Future: Global and Local Challenges, 2009.

[48] Y. Lu and R. G. Lueck, "Using a broadband ADCP in a tidal channel. Part II: Turbulence," Journal of Atmospheric and Oceanic Technology, vol. 16, no. 11, pp. 1568-1579, 1999.

[49] T. P. Rippeth, E. Williams, and J. H. Simpson, "Reynolds stress and turbulent energy production in a tidal channel," Journal of Physical Oceanography, vol. 32, no. 4, pp. 1242-1251, 2002.

[50] S. C. Tatum, C. H. Frost, M. Allmark, D. M. O’doherty, A. Mason-Jones, P. W. Prickett, R. I. Grosvenor, C. B. Byrne, and T. O'Doherty, "Wave-current interaction effects on tidal stream turbine performance and loading characteristics," International Journal of Marine Energy, vol. 14, pp. 161-179, 2016. 
- The first study of ambient turbulence in Alderney Race is provided.

- Two independent methods are used to quantify turbulence metrics.

- Removal of wave and Doppler noise-induced bias is a crucial step.

- The integral lengthscale was found to be 2-3 times the local water depth.

- Unique dataset of turbulence metrics computed at mid-depth are provided. 


\section{DISCLOSURE OF POTENTIAL CONFLICT-OF-INTEREST}

All accepted articles will be published only after the signed disclosure statements have been completed. The information will be published as a footnote to the article on the Title page. The signatorv assures the statements are true for all authors.

\section{PLEASE RESPOND TO EACH OF THE FOLLOWING OUESTIONS BY CHECKING THE} APPROPRIATE BOXES:

1. Did any author of the manuscript receive funding, grants, or in-kind support in support of the research or the preparation of the manuscript?

$\mathrm{X}$ NO

I_ YES, support received from the following persons, agencies, industrial or commercial parties is disclosed below.

If yes, did the support include contractual or implied restriction on utilization or publication of the data and/or review of the data prior to publication?
$\mathrm{X} \mathrm{NO}$
1 Y YES

2. Did any author have association or financial involvement (i.e. consultancies/advisory board, stock ownerships/options, equity interest, patents received or pending, royalties/honorary) with any organization or commercial entity having a financial interest in or financial conflict with the subject matter or research presented in the manuscript?

\section{$\mathrm{X} \mathrm{NO}$}

$/$ I YES, the association or financial involvement of individual authors is disclosed below.

1.

2 .

3.

(use additional sheets if necessary) 
Author Name: Maxime Thiébaut (on behalf of all authors)

Title of Article: A comprehensive assessment of turbulence, and methods of measurement with ADCP, at a tidal-stream energy site influenced by wind-generated ocean waves

Manuscript Number: EGY-D-19-03681

Date: $30 / 10 / 2019$

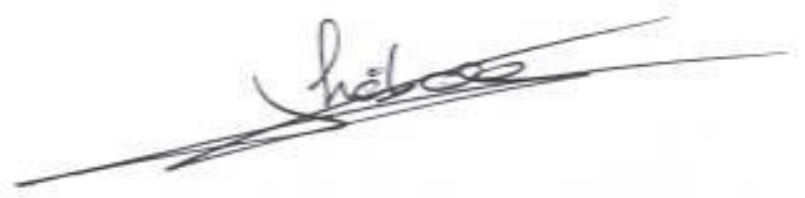

